Atmos. Chem. Phys. Discuss., 6, 3093-3097, 2006

www.atmos-chem-phys-discuss.net/6/3093/2006/

(c) Author(s) 2006. This work is licensed

under a Creative Commons License.

\title{
Methane production from mixed tropical savanna and forest vegetation in Venezuela
}

P. J. Crutzen ${ }^{1,2}$, E. Sanhueza ${ }^{3}$, and C. A. M. Brenninkmeijer ${ }^{1}$

${ }^{1}$ Max Planck Institute for Chemistry, Mainz, Germany

${ }^{2}$ Scripps Institution of Oceanography, University of California, San Diego, USA

${ }^{3}$ Instituto Venezolano de Investigaciones Científicas, Caracas, Venezuela

Received: 21 March 2006 - Accepted: 25 March 2006 - Published: 13 April 2006

Correspondence to: C. A. M. Brenninkmeijer (carlb@mpch-mainz.mpg.de)
Methane production from savanna

vegetation

P. J. Crutzen et al.

\section{ACPD}

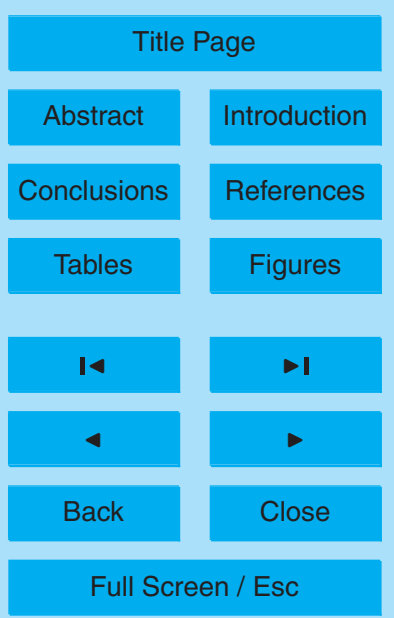

Printer-friendly Version

Interactive Discussion 


\section{Abstract}

Measurements of methane concentrations in the boundary layer in the northern part of the Guayana shield, Venezuela, during the wet season (October 1988), showed the presence of substantial methane surface emissions. The measuring site is within the

5 savanna climate region, but is affected by emissions from savanna and forest vegetation. From day versus night concentration measurements, with higher concentrations during night, a methane source strength near the site of $3-7 \times 10^{11}$ molecules $/ \mathrm{cm}^{2} / \mathrm{s}$ can be estimated, which includes emissions from small tracts of flooded soils, termites and especially tropical vegetation. Extrapolated to the entire savanna, this may imply 10 a methane source of $\sim 30-60 \mathrm{Tg} \mathrm{yr}^{-1}$ similar to the one calculated for tropical vegetation on the basis of recently published in vitro plant emission experiments by Keppler et al. (2006), which indicate emissions of $\sim 30 \mathrm{Tg} \mathrm{yr}^{-1}$ for tropical savannas and grasslands and $\sim 78 \mathrm{Tg} \mathrm{yr}^{-1}$ for tropical forests.

\section{Introduction}

15 The finding by Keppler et al. (2006) of methane production under aerobic conditions by leaves of living plants is a striking discovery in biological and atmospheric chemistry with implications also for climate. Extrapolating from their measurements in incubation chambers to global conditions, using net primary production in various ecosystems as a metric, they derive a global $\mathrm{CH}_{4}$ production rate of $62-236 \mathrm{Tg} /$ year of methane, which is $10-40 \%$ of the total methane production rate. With the biochemical mechanism still unknown, and the assessment of the implications for the global methane budget depending on how to properly upscale their in vitro results, considerable discussions undoubtedly will follow. Here we reanalyzed 18 year old data, obtained in the Venezuelan savanna climate region that, as we will see, support the occurrence of large methane emission estimates from plants as first reported by Keppler et al. (2006). A map showing the region (Koeppen classification) can be found in Sanhueza et al. (1988). The
6, 3093-3097, 2006

Methane production from savanna vegetation

P. J. Crutzen et al.

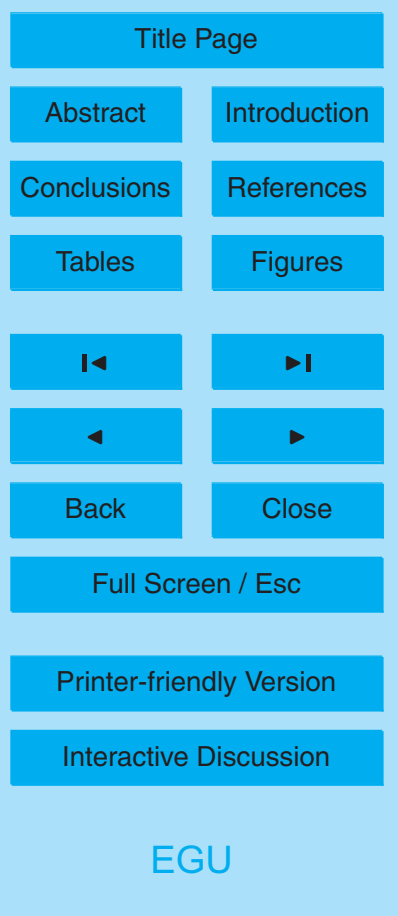


environmental conditions in the Orinoco savanna region have been published by Sanhueza and Crutzen (1998). For a description of the experimental setup and local conditions at the Guri site, we refer to Scharffe et al. (1990).

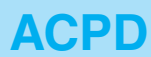

6, 3093-3097, 2006

\section{Results and discussion}

5 Because the measurements by Keppler et al. (2006) were conducted on a laboratory scale, up-scaling to the globe causes major uncertainties. Here we reanalyze and reinterpret data obtained during a field campaign 18 years ago in October 1988, in the Venezuelan savanna climatic region during the wet season, first reported by Scharffe et al. (1990), which support the occurrence of high $\mathrm{CH}_{4}$ production rates from vegetation. In Fig. 1 we reprint measurement results, showing the accumulation of methane during the night under a $100 \mathrm{~m}$ high inversion layer (Octavio et al., 1987). From these data a nocturnal production of $\mathrm{CH}_{4}$ of $(3-7) \times 10^{11}$ molecules $/ \mathrm{cm}^{2} / \mathrm{s}$ was derived. As indicated in the Scharffe et al. paper the savanna measuring site was located nearby $(\leq 1 \mathrm{~km})$ a forest, therefore, the $\mathrm{CH}_{4}$ data presented in Fig. 1 are most likely affected by both 15 savanna and forest emissions.

Assuming similar methane production rates during the day, which might be an underestimate, an extrapolation of these data to all savanna regions with a total area of $15 \times 10^{6} \mathrm{~km}^{2}$ during the wet season (Bolin et al., 1979) yields a $\mathrm{CH}_{4}$ production of at least $30 \mathrm{Tg} / \mathrm{year}$. A similar source during the dry season would double the estimated $20 \mathrm{CH}_{4}$ source. While Scharffe et al. (1990) invoked termites and small pools as sources of methane, in light of the discovery by Keppler et al. (2006), it now seems likely that the methane emissions largely came from the savanna and forest vegetation. It is interesting to note that the ratios between $\mathrm{CH}_{4}$ production and net primary productivity (Bolin et al., 1979) for the field measurements were in the order of 0.002-0.004, similar

Methane production from savanna vegetation

P. J. Crutzen et al.

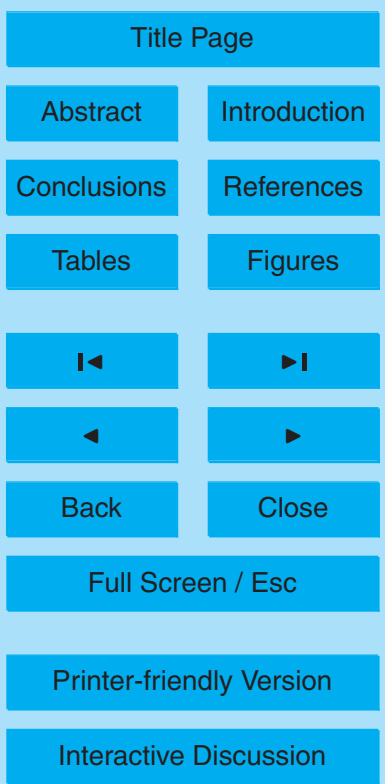




\section{Conclusion}

Our old field data are thus in favor of the large $\mathrm{CH}_{4}$ production rates from vegetation as derived by Keppler et al. (2006), which were based on wide extrapolations from the laboratory to the globe. The concentrations of $\mathrm{CH}_{4}$ of at least about $1.78 \mathrm{ppmv}$ that 5 were measured in the savanna region, compared to a global background value for 1988 of $1.67 \mathrm{ppmv}$ is a further indication of a large tropical source of methane. Further field studies are needed to clarify and quantify methane emissions from savanna vegetation to establish whether the extrapolations to large scale ecosystems are valid.

\section{References}

Bolin, B., Degens, E. T., Duvigneau, P., and Kempe, S.: The global biogeochemical carbon cycle, in: The Global Carbon Cycle, edited by: Bolin, B., Wiley-Chichester, 1-56, 1979.

Keppler, F., Hamilton, J. T. G., Brass, M., and Röckmann, T.: Methane emissions from terrestrial plants under aerobic conditions, Nature, 439, 187-191, 2006.

Octavio, K. H., Arrocha, A., and Sanhueza, E.: Low nocturnal atmospheric dispersion capacity of the Venezuela savannah, Tellus, 39B, 286-292, 1987.

Sanhueza, E., Cuenca, G., Gomez, M. J., Herrera, R., Ishizaki, C., Martí, I., and Paolini, J.: Characterization of Venezuelan Environment and its Potential for Acidification, in: Acidification in Tropical Countries, edited by: Rodhe, H. and Herrera, R., John Wiley and Sons, 197-255, 1988.

20 Sanhueza, E. and Crutzen, P. J.: Budget of Fixed Nitrogen in the Orinoco Savannah Region: The Role of Pyrodenitrification, Global Biogeochem. Cycles, 12, 653-666, 1998.

Scharffe, D., Hao, W. M., Donoso, L., Crutzen, P. J., and Sanhueza, E.: Soil fluxes and atmospheric concentration of $\mathrm{CO}$ and $\mathrm{CH}_{4}$ in the northern part of the Guayana Shield, Venezuela, J. Geophys. Res., 95, 22 475-22 480, 1990.

Methane production from savanna vegetation

P. J. Crutzen et al.

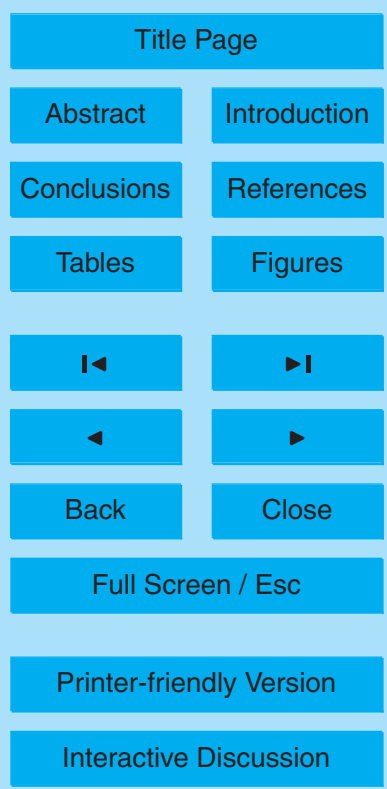




\section{ACPD}

\section{6, 3093-3097, 2006}

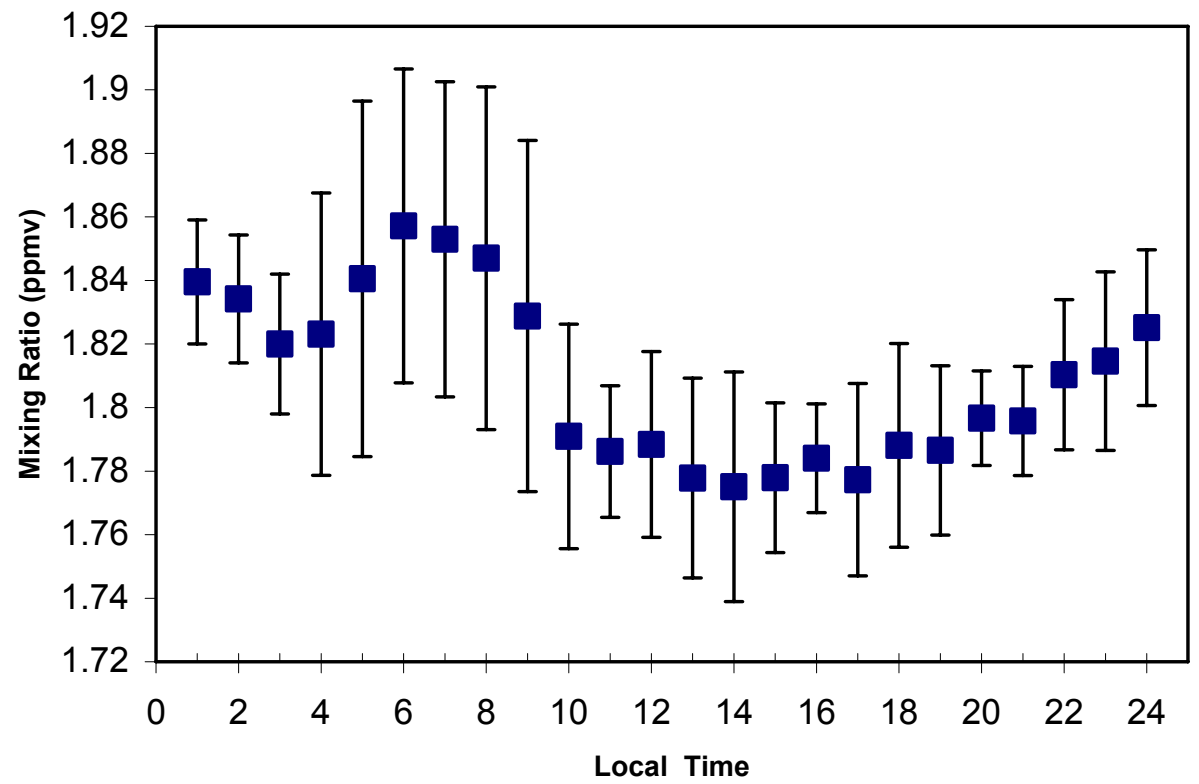

Methane production from savanna vegetation

P. J. Crutzen et al.

Title Page

Abstract

Introduction

Conclusions References

Tables

Figures

14

$>1$

4

Back

Close

\section{Full Screen / Esc}

Printer-friendly Version

Interactive Discussion 